Tropical Journal of Pharmaceutical Research November 2021; 20 (11): 2413-2418

ISSN: $1596-5996$ (print); 1596-9827 (electronic)

(C) Pharmacotherapy Group, Faculty of Pharmacy, University of Benin, Benin City, 300001 Nigeria

Available online at http://www.tjpr.org

Original Research Article

http://dx.doi.org/10.4314/tjpr.v20i11.25

\title{
Effect of capecitabine combined with irinotecan on the safety of colon cancer treatment, patients' adverse reactions and quality of life
}

\author{
Mingjuan Fan, Qing Li, Weijie Zhong, Shuang He, Kangbao Li* \\ Department of Geriatric Medicine, Guangzhou First People's Hospital, School of Medicine, South China University of \\ Technology, Guangzhou 510180, China
}

*For correspondence: Email: kn3cpv@163.com

Sent for review: 10 July 2021

Revised accepted: 18 October 2021

\begin{abstract}
Purpose: To study the impact of the combination of capecitabine and irinotecan on the safety of colon cancer treatment, adverse reactions and wellbeing of patients.

Methods: Colon cancer subjects $(n=120)$ admitted to Guangzhou First People's Hospital, Guangzhou, China were assigned equally to two groups ( $A$ and $B)$ according to their order of admission, and they received intravenous infusion of irinotecan. In addition, group $A$ patients were administered capecitabine, but those in $B$ group were given tegafur, gimeracil and oteracil porassium. The patients in groups $A$ and $B$ were compared with respect to the incidence of unwanted effects, quality of life (QoL), and overall clinical efficacy of the treatments.

Results: Cases of nausea and vomiting, delayed diarrhea and sensory neuropathy of the patients were significantly reduced in group $A$, relative to group $B$. Moreover, QoL score after treatment was markedly higher in group $A$ than in group $B$, while the objective response rate (ORR) of colon cancer patients in group $A$ was also significantly higher than that in group $B(p<0.05)$. However, no obvious difference in disease control rate (DCR) was observed between groups $A$ and $B(p>0.05)$.

Conclusion: Combined capecitabine and irinotecan therapy effectively improves clinical prognosis, reduces the incidence of adverse reactions, and is safe in colon cancer patients. Therefore, the combined treatment may be beneficial in the management of colon cancer.
\end{abstract}

Keywords: Capecitabine, Irinotecan, Adverse reactions, Quality of life (QoL), Colon cancer

\begin{abstract}
This is an Open Access article that uses a funding model which does not charge readers or their institutions for access and distributed under the terms of the Creative Commons Attribution License (http://creativecommons.org/licenses/by/4.0) and the Budapest Open Access Initiative (http://www.budapestopenaccessinitiative.org/read), which permit unrestricted use, distribution, and reproduction in any medium, provided the original work is properly credited.

Tropical Journal of Pharmaceutical Research is indexed by Science Citation Index (SciSearch), Scopus, International Pharmaceutical Abstract, Chemical Abstracts, Embase, Index Copernicus, EBSCO, African Index Medicus, JournalSeek, Journal Citation Reports/Science Edition, Directory of Open Access Journals (DOAJ), African Journal Online, Bioline International, Open-J-Gate and Pharmacy Abstracts
\end{abstract}

\section{INTRODUCTION}

Colon cancer patients are often at the midway or advanced phases of carcinogenesis when diagnosed. Surgical treatment is generally used in clinical practice as the primary treatment modality for colon cancer. However, due to the sub-optimal degree of resection during surgeries, the patients also need to rely heavily on chemotherapy to improve their prognosis, which often brings toxic and side effects and symptoms e.g., diarrhea, thereby adversely affecting daily lives of patients [1-3]. Nowadays, people pay more attention to drug safety, and many new types of fluorouracil have been applied in clinical practice. Capecitabine, a fluorouracil drug, is an 
anti-tumor drug which improves overall efficacy, with less toxic and side effects on patients. Moreover, irinotecan, a popular drug for colon cancer, effectively facilitates enzymatic activity involved in metabolism of capecitabine. Therefore, these two drugs may exert good synergistic effects [4-6]. Based on this, the present study was on the influence of combined use of capecitabine and irinotecan in the treatment of 120 colon cancer subjects.

\section{METHODS}

A total of 120 colon cancer patients admitted to Guangzhou First People's Hospital, Guangzhou, China were assigned equally to two groups ( $A$ and $B$ ) according to their order of admission. There were no significant differences in the general profile of the two groups $(p>0.05)$.

\section{Inclusion criteria}

Patients and their families were informed about the scope of the research, and duly signed informed consent was obtained from them. Approval for this investigation was received from the Ethical Committee of Guangzhou First People's Hospital (approval no. 20181113), and the study followed the guidelines of Declaration of Helsinki as revised in 2013 [7]. Patients who were diagnosed with colon cancer after rectal touch, fibro-colonoscope and histopathologic examination were included in this study.

\section{Exclusion criteria}

Patients with mental disorders or who could not communicate with others; patients with other organic diseases, those aged over 75 years, patients with tumor metastasis, pregnant and lactating patients, and patients with expected survival period of less than or equal to 12 weeks, were excluded.

\section{Treatments}

Baseline examinations were carried out in all patients, including pathological examination, imaging examination (CT of thoracoabdominal region), blood routine examination, as well as liver and kidney function examination. Data on signs were recorded so as to confirm final treatment regimens for the patients.

Patients in both groups received intravenous infusion of irinotecan. In addition, the group $A$ patients were administered capecitabine, while subjects in group B were given tegafur, gimeracil and oteracil potassium. The specific steps were as follows.

\section{Irinotecan treatment}

On the first day of chemotherapy, the patients were treated with $0.5 \mathrm{mg}$ of atropine (Hunan Dongting Pharmaceutical Co. Ltd; National Medical Products Administration approval number: H43020586), and after $0.5 \mathrm{~h}$, they received irinotecan (Shandong Luoxin Pharmaceutical Group Hengxin Pharmaceutical Co. Ltd.; National Medical Products Administration approval number: H20113455) at a dose of $160 \mathrm{mg} / \mathrm{m}^{2}$ via intravenous infusion within $1 \mathrm{~h}$. One course of treatment lasted 3 weeks, and the patients were treated in six courses.

Table 1: Comparison of the general profile of Group A and B patients

\begin{tabular}{|c|c|c|c|c|}
\hline Variable & Group A (n=60) & Group B $(n=60)$ & $x^{2 / t}$ & $P$-value \\
\hline Gender & & & 0.034 & 0.853 \\
\hline Male & 35 & 34 & & \\
\hline Female & 25 & 26 & & \\
\hline \multicolumn{5}{|l|}{ Age (years) } \\
\hline Age range & $32-74$ & $33-74$ & & \\
\hline Average age & $56.21 \pm 6.20$ & $56.23 \pm 6.21$ & 0.018 & 0.986 \\
\hline $\begin{array}{l}\text { Pathological } \\
\text { classification }\end{array}$ & & & & \\
\hline $\begin{array}{l}\text { Moderately } \\
\text { differentiated } \\
\text { adenocarcinoma }\end{array}$ & 21 & 20 & 0.037 & 0.847 \\
\hline $\begin{array}{l}\text { Poorly } \\
\text { differentiated } \\
\text { adenocarcinoma }\end{array}$ & 20 & 22 & 0.147 & 0.702 \\
\hline $\begin{array}{l}\text { Mucinous cell } \\
\text { carcinoma }\end{array}$ & 12 & 11 & 0.054 & 0.817 \\
\hline $\begin{array}{l}\text { Signet ring cell } \\
\text { carcinoma }\end{array}$ & 7 & 7 & 0.000 & 1.000 \\
\hline
\end{tabular}




\section{Capecitabine treatment}

The patients orally took capecitabine (Lianyungang Runzhong Pharmaceutical Co. Ltd; National Medical Products Administration approval number: H2012345) at a dose of 750 $\mathrm{mg} / \mathrm{m}^{2}$ in the morning and evening after meals daily, and the drug administration was stopped for 1 week after every 2 weeks.

Treatment with tegafur, gimeracil and oteracil potassium

The patients took tegafur, gimeracil and oteracil porassium (Qilu Pharmaceutical Co. Ltd.; National Medical Products Administration approval number: H20100151) at a dose of 20 $\mathrm{mg} / \mathrm{m}^{2}$ daily and orally in the morning and evening, after meals. The drug was discontinued for 1 week after every 2 weeks.

The patients were given specific treatment measures based on their conditions during the study, so as to protect their gastrointestinal function.

\section{Evaluation of clinical indices}

\section{Incidence of adverse reactions}

Adverse reactions consisted of myelosuppression, nausea and vomiting, delayed diarrhea and sensory neuropathy. According to the Common Terminology Criteria for Adverse Events of US National Cancer Institute $(\mathrm{NCl})$, toxic and side reactions in patients were classified as grade I (mild reactions), grade II (obvious reactions but no effect on life), grade III (severe reactions and effect on life), and grade IV (severe reactions and serious effects on life). The number of patients in each of the different grades was recorded [8].

QOL

This was determined with the Karnofsky performance score (KPS). The higher the score, the better the quality of life [9].

\section{Overall efficacy}

Patients' conditions were classified as complete response (CR), partial response (PR), stable disease (SD) and progressive disease (PD) according to the WHO Response Evaluation Criteria [10].

$\mathrm{ORR}=\mathrm{CR}+\mathrm{PR}$

$\mathrm{DCR}=\mathrm{CR}+\mathrm{PR}+\mathrm{SD}$

where DCR = disease control rate of GC; ORR = overall response rate; $\mathrm{CR}=$ complete response; $\mathrm{PR}=$ partial response; and $\mathrm{SD}=$ stable disease .

\section{Statistical analysis}

The selected data processing software used in this study was SPSS20.0, while GraphPad Prism 7 was selected for drawing graphs. Measured data were analyzed with Student's $t$-test, while counting data were analyzed using $x^{2}$ test. Value of $p<0.05$ indicated statistically significant differences.

\section{RESULTS}

\section{Incidence of adverse reactions}

Table 2 shows that there were no marked differences in cases of myelosuppression between patients in groups $A$ and $B\left(X^{2}=1.600\right.$, $p=0.206)$.

\section{Incidence of nausea and vomiting}

Nausea and vomiting occurred in 27 patients $(45.0 \%)$ in group A, relative to 40 patients $(66.7$ $\%)$ in B group i.e., cases of nausea and vomiting were markedly lower in group $A\left(X^{2}=5.711, p=\right.$ 0.017), as shown in Figure 1.

\section{Incidence of delayed diarrhea}

Table 3 shows that cases of delayed diarrhea were markedly reduced in group $A$, relative to $B$ group $\left(x^{2}=4.227, p=0.040\right)$.

Table 2: Incidence of myelosuppression in patients [n (\%)]

\begin{tabular}{lcccccc}
\hline Group & Grade I & Grade II & Grade III & Grade IV & $\begin{array}{c}\text { No } \\
\text { myelosuppression }\end{array}$ & $\begin{array}{c}\text { Total } \\
\text { incidence }\end{array}$ \\
\hline A & $4(6.7)$ & $4(6.7)$ & $3(5.0)$ & $1(1.7)$ & $48(80.0)$ & $12(20.0)$ \\
B & $4(6.7)$ & $6(10.0)$ & $4(6.7)$ & $4(6.7)$ & $42(70.0)$ & $18(30.0)$ \\
$X^{2}$ & 0.000 & 0.436 & 0.152 & 1.878 & 1.600 & 1.600 \\
$P$-value & 1.000 & 0.509 & 0.697 & 0.171 & 0.206 & 0.206 \\
\hline
\end{tabular}




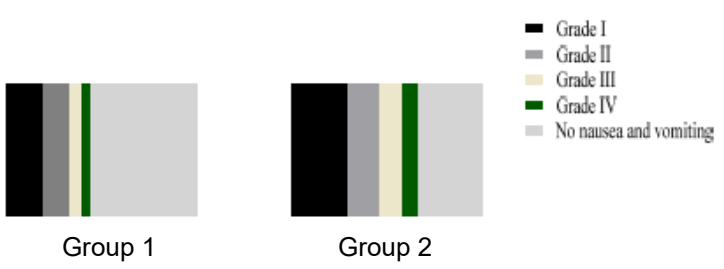

Figure 1: Comparison of the incidence of nausea and vomiting

\section{Incidence of sensory neuropathy}

Sensory neuropathy occurred in 7 patients (11.7 $\%$ ) in group $A$, and in 16 patients $(26.7 \%)$ in $B$ group. Cases of sensory neuropathy were markedly lower in group $A$ than in $B\left(X^{2}=4.357\right.$, $p=0.037$ ), as shown in Figure 2 .

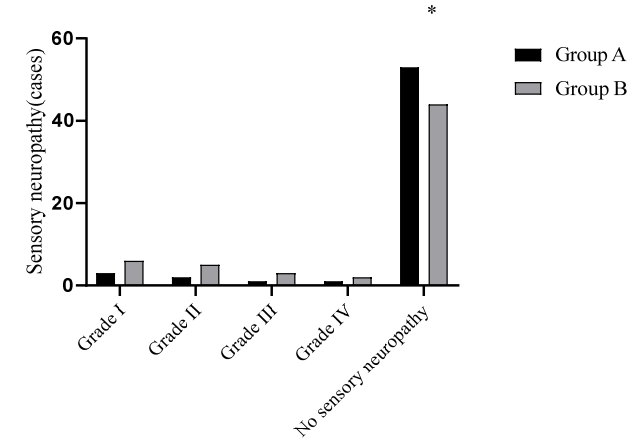

Figure 2: Comparison of the incidence of sensory neuropathy. ${ }^{*} P<0.05$
QOL of the patients

Table 3 shows that the KPS score after treatment in group $A$ was higher that the score in $B$ group $(p<0.001)$.

\section{Overall treatment efficacy}

The ORR of the patients was markedly higher in group $A$ than in $B$, but DCR values were comparable, as shown in Table 3.

\section{DISCUSSION}

At present, due to limited medical techniques in the treatment of colon cancer in China, patients still have to face the problems of severely reduced QOL after undergoing surgeries and systemic chemotherapy required to improve their prognosis. Chemotherapeutic drugs produce a variety of adverse effects in patients. These effects further lead to multiple complications in patients during chemotherapy. Therefore, it is of great significance to apply safer drugs in clinics $[11,12]$. Capecitabine is a novel antineoplastic agent, and a selective intra-tumoral activated fluorouracil urethane.

Studies have shown that its therapeutic efficacy is superior to those of conventional fluorouracil-

Table 3: Comparison of the incidence of the delayed diarrhea [n (\%)]

\begin{tabular}{lcccccc}
\hline Group & Grade I & Grade II & Grade III & Grade IV & $\begin{array}{c}\text { No delayed } \\
\text { diarrhea }\end{array}$ & $\begin{array}{c}\text { Total } \\
\text { incidence }\end{array}$ \\
\hline A & $1(1.7)$ & $1(1.7)$ & $1(1.7)$ & $0(0.0)$ & $57(95.0)$ & $3(5.0)$ \\
B & $4(6.7)$ & $3(5.0)$ & $2(3.3)$ & $1(1.7)$ & $50(83.3)$ & $10(16.7)$ \\
$X^{2}$ & 1.878 & 1.035 & 0.342 & 1.008 & 4.227 & 4.227 \\
$P$ & 0.171 & 0.309 & 0.559 & 0.315 & 0.040 & 0.040 \\
\hline
\end{tabular}

Table 4: KPS scores

\begin{tabular}{lccccc}
\hline Group A & Score & Group B & Score & $\boldsymbol{t}$ & $\boldsymbol{P}$-value \\
\hline Before treatment & $65.21 \pm 6.52$ & Before treatment & $65.22 \pm 5.89$ & 0.009 & 0.993 \\
After treatment & $76.89 \pm 5.41$ & After treatment & $69.56 \pm 5.25$ & 7.532 & 0.000 \\
$t$ & 10.679 & $t$ & 4.261 & & \\
$P$-value & 0.000 & $P$-value & 0.000 & & \\
\hline
\end{tabular}

Table 5: Comparison of the overall efficacy

\begin{tabular}{lcccccc}
\hline Group & $\begin{array}{c}\text { Complete } \\
\text { response }\end{array}$ & $\begin{array}{c}\text { Patial } \\
\text { response }\end{array}$ & $\begin{array}{c}\text { Stable } \\
\text { disease }\end{array}$ & PD & $\begin{array}{c}\text { Objective } \\
\text { response rate }\end{array}$ & $\begin{array}{c}\text { Disease } \\
\text { control rate }\end{array}$ \\
\hline $\mathrm{A}$ & 16 & 28 & 10 & 6 & 44 & 54 \\
$\mathrm{~B}$ & 9 & 20 & 18 & 13 & 29 & 47 \\
$X^{2}$ & 2.476 & 2.222 & 2.981 & 3.064 & 7.869 & 3.064 \\
$P$-value & 0.116 & 0.136 & 0.084 & 0.080 & 0.005 & 0.080 \\
\hline
\end{tabular}

based drugs. It effectively improved overall clinical outcomes. Irinotecan decreases the frequency of generation of tumor cell nucleic acid, and its combination with capecitabine works 
well, and it has high safety, with less toxic and side effects $[13,14]$.

In this study, the incidences of nausea and vomiting, delayed diarrhea as well as sensory neuropathy in group $A$ were markedly lower in group $A$ than in group $B$, indicating that relative to tegafur, gimeracil and oteracil porassium, capecitabine has mild effect on the gastrointestinal tract, because it rapidly neutralizes foreign bodies when fighting against tumors, and it exerts less stimulation of gastrointestinal function, resulting in lower incidence of nausea and vomiting.

In this study, ORR was markedly higher in group A than in B group because the combination of irinotecan and capecitabine exerted enhanced efficiency in antitumor effect. Irinotecan impairs the synthesis of tumor cell nucleic acid, while capecitabine slows down the recombination of tumor cell nucleic acid [15-17]. Therefore, the lesions disappeared faster in group $A$.

Moreover, the results of this study revealed that QOL after treatment was markedly increased in group $A$, relative to $B$ group, suggesting that safe and effective chemotherapeutic drugs are essential for optimizing patients' quality of life. In a study by Hiroi [18], it was reported that the KPS score in a group administered capecitabine plus irinotecan was $78.1 \pm 5.26$ points after treatment, which was significantly higher than the corresponding score in the control patients who received combination of apecitabine, tegafur, gimeracil and oteracil porassium. This indicates that the combination of capecitabine and irinotecan can effectively improve patients' QOL.

\section{CONCLUSION}

Combined treatment with capecitabine and irinotecan significantly relieves adverse reactions, improves QOL, and has high level of safety in colon cancer patients. Therefore, the combined treatment has merits over current treatment strategies.

\section{DECLARATIONS}

\section{Conflict of Interest}

No conflict of interest associated with this work.

\section{Contribution of Authors}

We declare that this work was done by the authors named in this article and all liabilities pertaining to claims relating to the content of this article will be borne by the authors. Mingjuan Fan conceived and designed the study, and drafted the manuscript. Qing $\mathrm{Li}$ and Weijie Zhong collected, analyzed and interpreted the experimental data. Shuang $\mathrm{He}$ and Kangbao $\mathrm{Li}$ revised the manuscript for important intellectual contents. All authors read and approved the final manuscript.

\section{Open Access}

This is an Open Access article that uses a funding model which does not charge readers or their institutions for access and distributed under the terms of the Creative Commons Attribution License (http://creativecommons.org/licenses/by/ 4.0) and the Budapest Open Access Initiative (http://www.budapestopenaccessinitiative.org/rea d), which permit unrestricted use, distribution, and reproduction in any medium, provided the original work is properly credited.

\section{REFERENCES}

1. Iwauchi T, Uchima $Y$, Matsutani S, Tanaka H, Okada T, Miyamoto $H$, Tsujio $G$, Kurihara $S$, Nagashima D, Hirakawa $T$, et al. Hemorrhage of Peritoneal Dissemination of the Ascending Colon Cancer Successfully Controlled by Palliative Radiotherapy-A Case Report. Gan To Kagaku Ryoho 2020; 47: 19631965.

2. Saif $M W$. Capecitabine-induced cerebellar toxicity and TYMS pharmacogenetics. Anticancer Drugs 2019; 30: 431-434.

3. Larsen FO, Markussen A, Diness LV, Nielsen D. Efficacy and Safety of Capecitabine, Irinotecan, Gemcitabine, and Bevacizumab as Second-Line Treatment in Advanced Biliary Tract Cancer: A Phase II Study. Oncol 2018; 94: 19-24.

4. Behourah Z, Bousahba A, Djellali L. P-250Capecitabine, irinotecan, and bevacizumab in patients with previously untreated metastatic colorectal cancer: Experience of the oncology department of the university hospital of Oran, Algeria. Ann Oncol 2018; 29.

5. Zeynali-Moghaddam S, Mohammadian M, Kheradmand $F$, Fathi-Azarbayjani A, Rasmi Y, Esna-Ashari O, Malekinejad $H$. A molecular basis for the synergy between 17allylamino17demethoxy geldanamycin with Capecitabine and Irinotecan in human colorectal cancer cells through VEFG and MMP-9 gene expression. Gene 2019; 684: 30-38.

6. Kudo T, Takemasa I, Hata T, Sakai D, Takahashi H, Haraguchi N, Nishimura J, Hata T, Matsuda C, Satoh T, et al. A Phase I Study of Neoadjuvant Capecitabine, Oxaliplatin, and Irinotecan (XELOXIRI) in Patients with Locally Advanced Rectal Cancer. Oncol 2019; 97: 1-6.

7. World Medical Association. World Medical Association Declaration of Helsinki: ethical principles for medical Trop J Pharm Res, November 2021; 20(11): 2417 
research involving human subjects. JAMA. 2013 Nov 27;310(20):2191-4. doi: 10.1001/jama.2013.281053. PMID: 24141714.

8. Gelibter AJ, Caponnetto $S$, Urbano $F$, Emiliani $A$, Scagnoli S, Sirgiovanni G, Napoli VM, Cortesi E. Adjuvant chemotherapy in resected colon cancer: When, how and how long? Surg Oncol 2019; 30: 100107.

9. Sinha $P$, Udhumansha U, Rathnam G, Ganesh M, Jang HT. Capecitabine encapsulated chitosan succinatesodium alginate macromolecular complex beads for colon cancer targeted delivery: in vitro evaluation. Int $J$ Biol Macromol 2018; 117: 840-850.

10. Attard CL, Maroun JA, Alloul K, Grima DT, Bernard LM. Cost-effectiveness of oxaliplatin in the adjuvant treatment of colon cancer in Canada. Curr Oncol 2010; 17: 17-24.

11. Price TJ. Modified XELIRI (capecitabine plus irinotecan) for metastatic colorectal cancer. Lancet Oncol 2018; 19: 587-589.

12. Zeynali-Moghaddam S, Mohammadian M, Kheradmand F, Fathi-Azarbayjani A, Rasmi Y, Esna-Ashari O, Malekinejad H. A molecular basis for the synergy between 17?allylamino?17?demethoxy geldanamycin with Capecitabine and Irinotecan in human colorectal cancer cells through VEFG and MMP-9 gene expression. Gene 2019; 684: 30-38.

13. Anvari S, Alimoghaddam K, Kasaeian A. Efficacy and Safety of the Irinotecan, Capecitabine, and Oxaliplatin
(IOX) Regimen in Metastatic Gastric Cancer: A Single Arm Phase II Trial. Middle East J Cancer 2019; 10: 916.

14. Saif MW. Capecitabine-induced cerebellar toxicity and TYMS pharmacogenetics. Anticancer Drugs 2019; 30: 431-434.

15. Okagawa $Y$, Sagawa $T$, Sakurada A, Uemura $N$, Hamaguchi K, Tamura F, Fujikawa K, Takahashi Y. [CapeOX Therapy as a Salvage Treatment for Advanced Gastric Cancer Refractory to S-1, Cisplatin, Irinotecan, and Taxanes]. Gan To Kagaku Ryoho 2018; 45: 1615-1618.

16. Moretto R, Corallo S, Belfiore A, Rossini D, Boccaccino $A$, Lonardi S, Centonze G, Morano F, Germani MM, Loupakis $F$, et al. Prognostic impact of immunemicroenvironment in colorectal liver metastases resected after triplets plus a biologic agent: $A$ pooled analysis of five prospective trials. Eur J Cancer 2020; 135: 78-88.

17. Dominic JL, Feroz SH, Muralidharan A, Ahmed A, Thirunavukarasu P. Aberrant Partial Chromosomal Instability With Chemotherapeutically Resistant Metachronous Colorectal Cancer Following a Synchronous Primary Colorectal Cancer: A Case Report. Cureus 2020; 12: e11308.

18. Hiroi S. Capecitabine Plus Irinotecan for Colon Cancer: Case Report and Literature Review. In vivo (Athens, Greece)2018; 32. 